\title{
Analysis of dilatation waves propagation in an irregular single-walled carbon nanotube under initial compressional stresses
}

\author{
Mahmoud Selim ${ }^{1}$ \\ ${ }^{1}$ Prince Sattam bin Abdulaziz University
}

August 11, 2020

\begin{abstract}
This work is the first attempt to show the impacts of irregularity and compressional initial stresses on the dilatation waves propagating in a single-walled carbon nanotube (SWCNT) with the use of Donnell thin shell approach. The irregularity is taken in the parabolic form at the surface of SWCNT. A new closed-form of the characteristics equation of the natural frequencies of propagation is derived and matched with the case of the absent of irregularity and compressional stresses effects. The theoretical analysis show that, the presence of irregularity and initial compressional stresses effects the natural frequency of dilatation waves propagating in SWCNT. The numerical results show that, the increasing of the initial stress and irregularity parameters decreasing the values of the natural frequencies of dilatation waves in SWCNTs. Thus, it can be concluded that, the investigation presented may be provide useful information for the next generation studies and accurate deigns of nanomachines and can be used as a useful reference for the designs of Nanodrive devices, Nanooscillators and Nanosensors.
\end{abstract}

\section{Hosted file}

selim.doc available at https://authorea.com/users/350288/articles/475157-analysis-ofdilatation-waves-propagation-in-an-irregular-single-walled-carbon-nanotube-underinitial-compressional-stresses

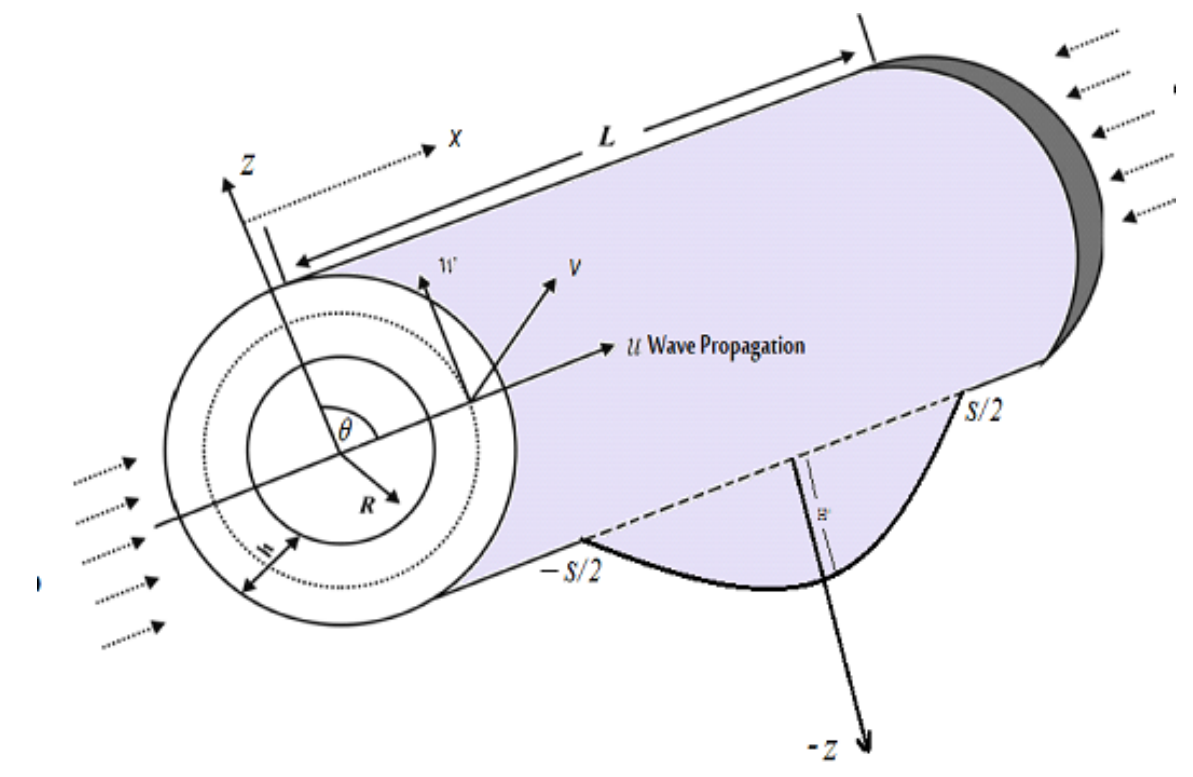



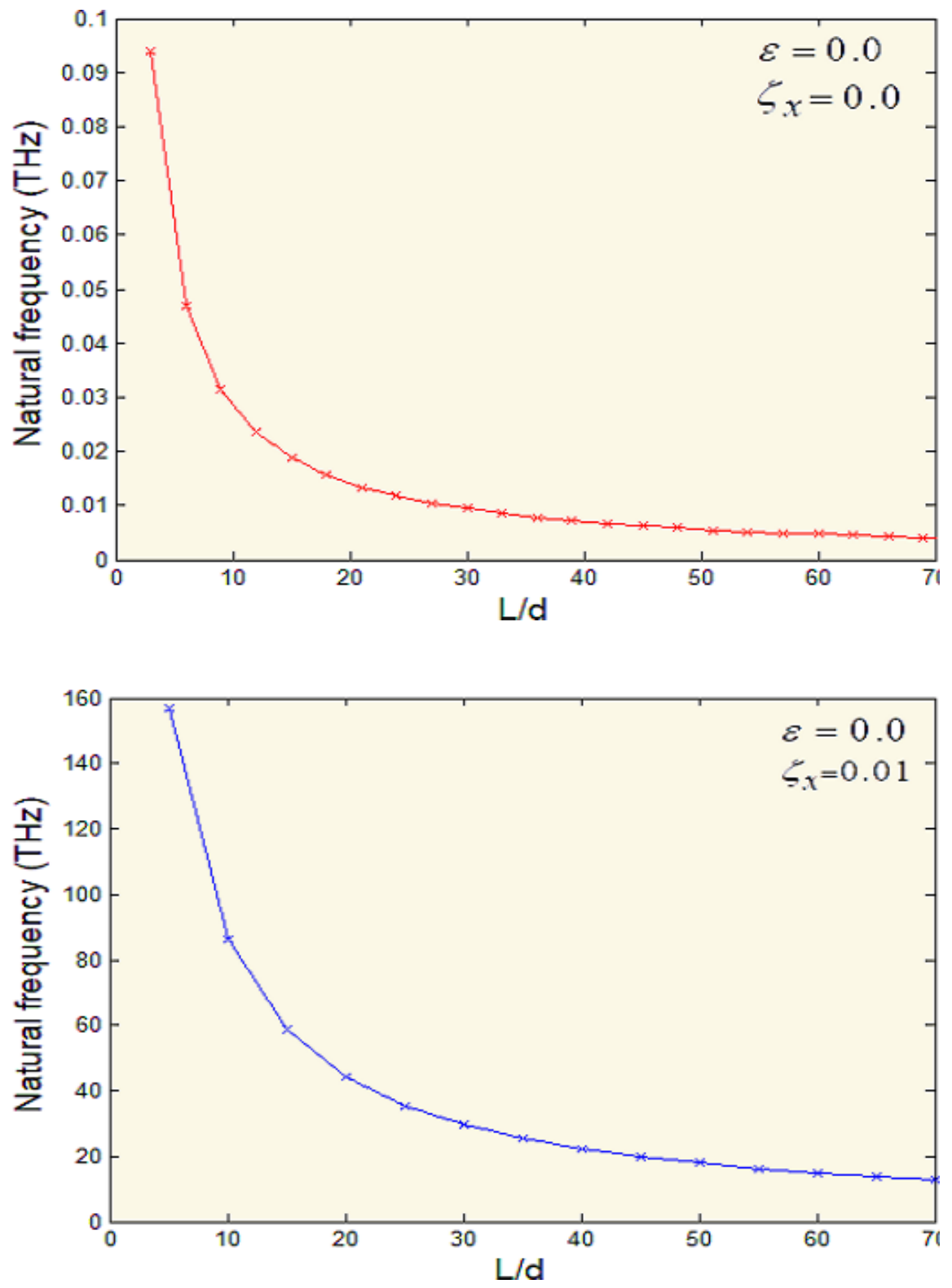

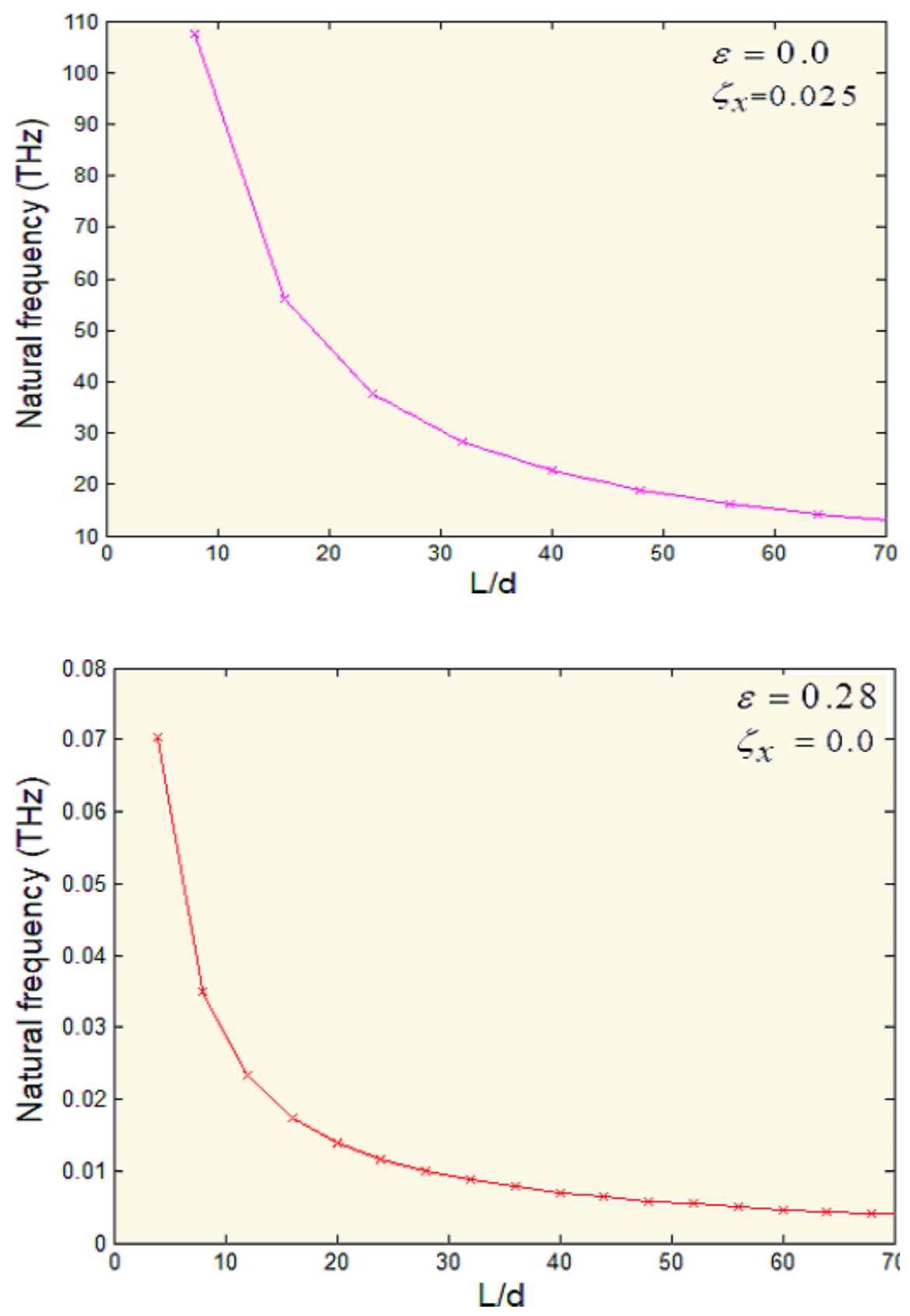

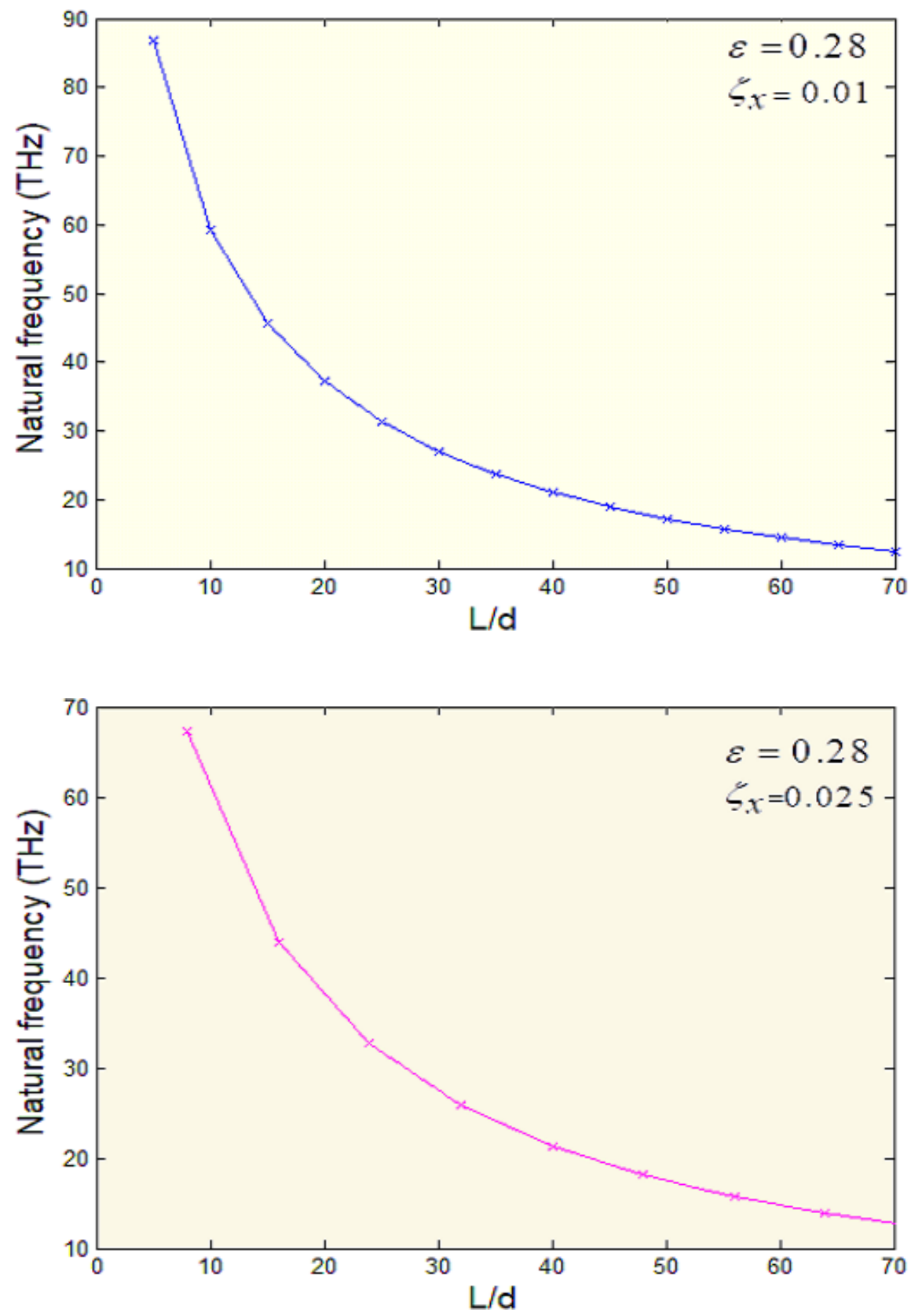

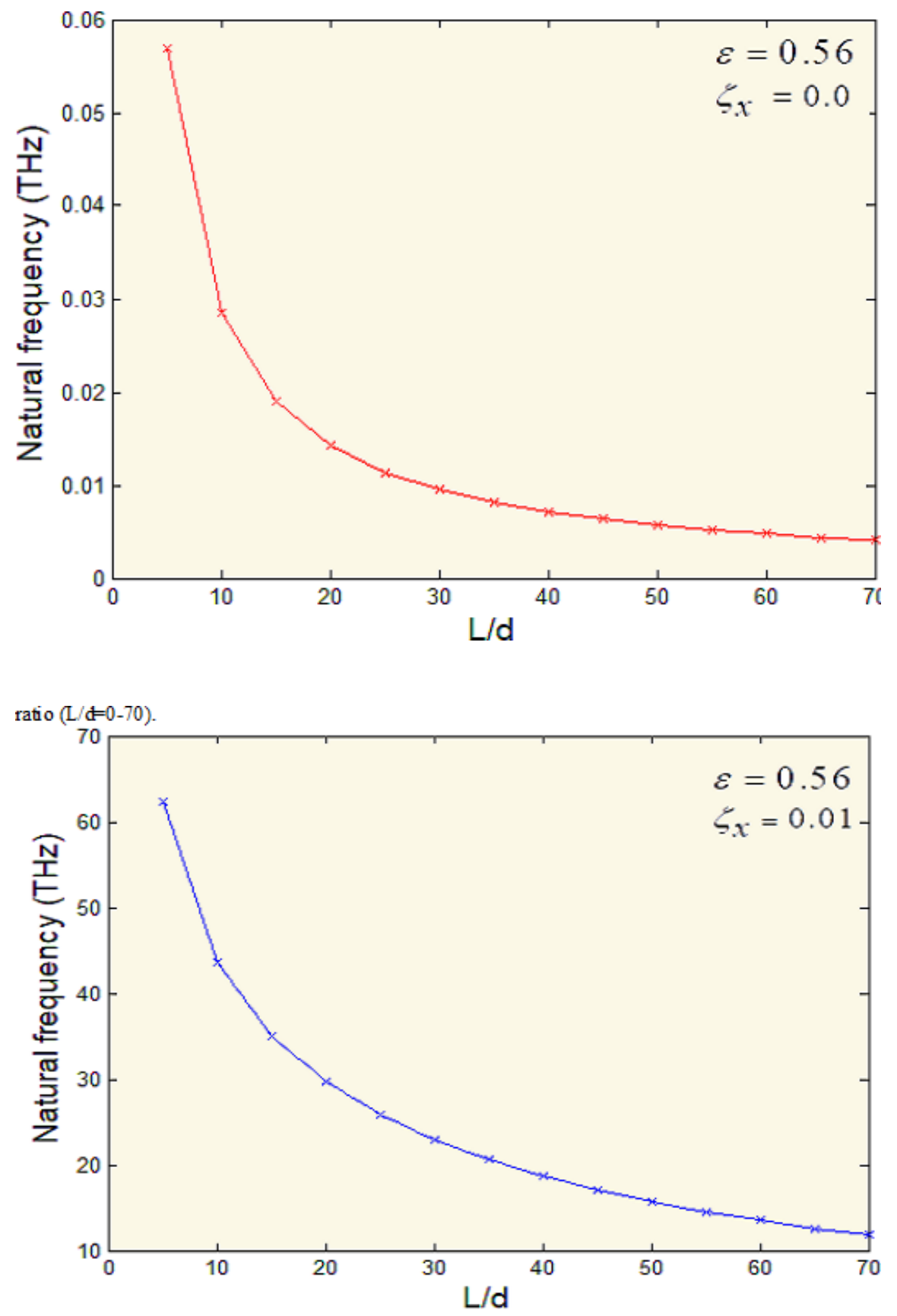


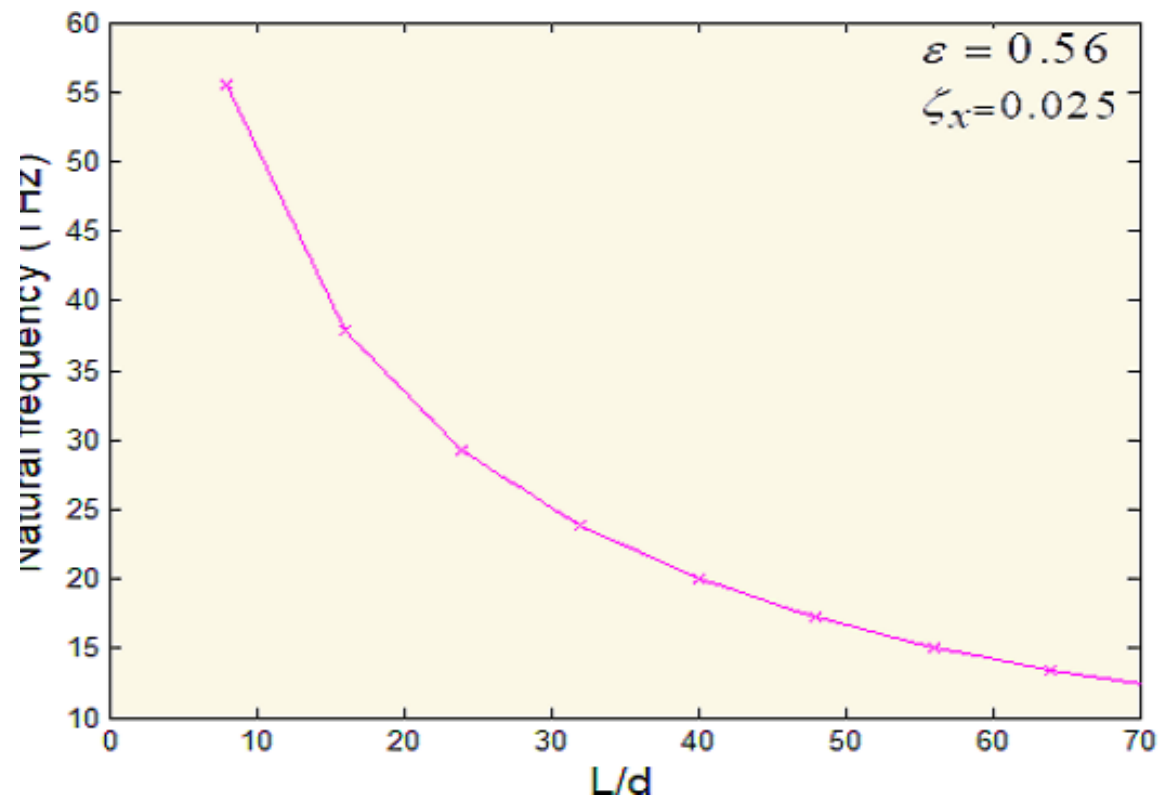

